Faith-Michael E. Uzoka*

Boluwaji A. Akinnuwesi**

\title{
DEVELOPMENT AND EVALUATION OF AN AHP MODEL FOR SOFTWARE SYSTEMS SELECTION
}

DOI: $10.22367 / \mathrm{mcdm} .2019 .14 .07$

\begin{abstract}
Decision-making in the field of information systems has become more complex due to larger number of alternatives, multiple and sometimes conflicting goals, and an increasingly uncertain environment. Software systems play unique roles in the translation of corporate strategic and tactical plans into actions. We present the results of a study designed to develop and evaluate an Analytical Hierarchy Process (AHP) model to support decision making in the selection of appropriate software system to meet organizational needs. Our results show the viability of the AHP methodology in software system/project selection, and points to the importance of functionality $(35.26 \%)$, quality $(22.00 \%)$ and usability $(19.34 \%)$ criteria in the overall decision process. Cost and vendor service did not seem to exert significant weight in the decision matrix.
\end{abstract}

Keywords: analytical hierarchy process, multi-criteria decision, software project, selection factors, functionality, cost.

\section{Introduction}

Software projects are complex and dynamic, comprising of a number of unstructured tasks that are affected by internal, external, and social factors (Meso et al., 2006). Software solutions to organizational needs are achieved through a systematic process of analysis, involving defining alternatives and selecting the best option in terms of software or software project (Hoffer, George and Valacich, 2016). A wrong software system/project selection could adversely

\footnotetext{
* Mount Royal University, Department of Mathematics and Computing, Calgary, Canada, e-mail: fuzoka@mtroyal.ca.

** University of Eswatini, Department of Computer Science, Kwaluseni M201, Eswatini (Swaziland), e-mail: moboluwaji@gmail.com.
} 
affect the organization's ability to function effectively and accomplish its strategic and tactical goals (Rouyendegh and Erkan, 2011; Uzoka et al., 2016). Software evaluation and selection is an intense activity, which could take months and several personnel in planning and deciding on critical concomitants that should go into the decision matrix. According to Uzoka et al. (2008) software evaluation and selection is a technology adoption decision, which revolves around product and organizational characteristics.

Software system selection decision involves multiple, sometimes conflicting objectives, and a blend of qualitative and quantitative criteria (Hwang and Yoon, 2012). The process of software selection is made difficult by the multiplicity of products, variation in product performance, and uncertainties of users' needs. The selection of inappropriate packages may compromise business processes, impact negatively on the functioning of the organization, and could jeopardize the very existence of the organization (Uzoka et al., 2016; Verville et al., 2002). Software products from different backgrounds are likely to exhibit different strengths and weaknesses; therefore, it is essential to employ methodical means for evaluating and selecting appropriate software that is cost effective and suits the business process needs, structure, culture, and environment of the organization. The existing structured methodologies for IS project selection range from single-criteria cost/benefit analysis (Hares et al., 1994) to multiple criteria scoring models (Melone et al., 1984), and ranking methods (Buss, 1983).

In this paper, we built on our previous works (Uzoka et al., 2016; Akinnuwesi and Uzoka, 2016) that identified variables that could be referenced by management in the evaluation of software project proposals. We recognize that the process of evaluating and selecting appropriate software project proposal for an organization is multi-criteria oriented and hence the use of AHP to prioritize and rank the proposals submitted for evaluation based on judgmental evaluation through peer ratings. The rest of the paper is organized as follows: in section 2 , we present the AHP methodology and the results of our exploratory factor analysis, which helped us reduce the variables into manageable factors; in section 3, we present the model evaluation and results, while in sections 4 and 5 , we present the limitations or the study and conclusion respectively.

The rest of the paper is organized as follows: in section 2, we present the AHP methodology and the results of our exploratory factor analysis, which helped us reduce the variables into manageable factors; in section 3, we present the model evaluation and results, while in sections 4 and 5, we present the limitations or the study and conclusion respectively.

\section{Research methodology}

This study adopted the classical AHP methodology (Saaty, 1977) in the development of a model for the evaluation software project, with the intent of 
selecting the best vendors/products. We developed three sets of questionnaires to obtain data for: 1) Identifying software project evaluation variable and carrying out factor analysis with the aim of reducing the variables to manageable factors; 2) Developing the AHP model; 3) Evaluating some software projects, based on the model. Our research methodology is depicted visually in Figure 1.

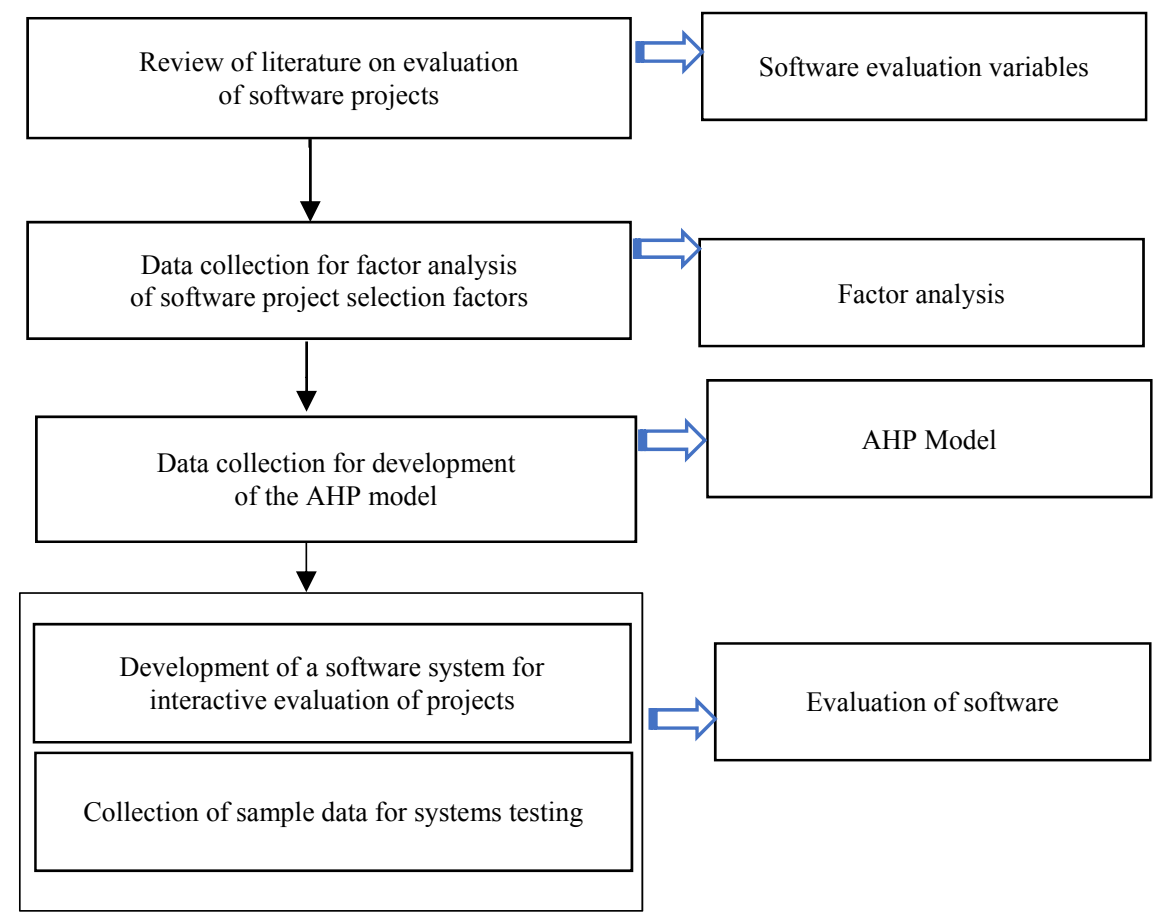

Figure 1: Research methodology

\subsection{Factor analysis}

The review of relevant literature on software and IT project evaluation produced 83 variables, which were utilized in the initial questionnaire, leading to factor analysis. The questionnaire had two sections (A and B). Section A consisted of respondent's demographic information, while section $\mathrm{B}$ evaluated the relevance of each of the 83 factors in software project evaluation. The variables were measured using a 5-point Likert-Type scale, ranging from 1-5. A total of 200 questionnaires were distributed physically and electronically via emails to individuals, who were directly or indirectly involved in IT/software projects in Nigeria. A total of 160 questionnaires $(80 \%)$ were correctly filled/returned and used for the factor analysis in SPSS. Our respondents consisted mainly of users $(88.8 \%)$ who had long years (5 year and above) experience in the use of software packages $(90.6 \%)$, mainly from ICT, communications, audit, and insurance (67\%). 
The exploratory factor analysis employed maximum likelihood extraction method to reduce the evaluation variables to a set of significant variables in the evaluation and selection of software. The KMO measure (0.534) and the Barlett's test of sphericity $(4749.152, p=0.00)$ point to the adequacy of data for factor analysis. Fourteen factors were extracted in more than 25 iterations with convergence $=0.072$. Applying the social science rule on the initial factor matrix generated, this did not give a meaningful factor loading. To obtain a meaningful factor loading, the initial matrix was rotated by orthogonal transformation by Quartimax with Kaiser Normalization. The rotated factor matrix provided a clear pattern of loading and was more meaningful for interpretation and therefore, used for the analysis. The rotated factor matrix produced fourteen factors: Module Content, User's Experience, Vendors Technical Know-how, Ease of Customization, Vendor Experience, System Adaptability, User Interest, Interoperability and Completeness, Reliability, Organizational Budget, Ease of Use, Integration, Cost of Implementation, System Efficiency. These factors and the variables that loaded on them, were utilized in the development of the AHP questionnaire for developing the AHP model.

\subsection{AHP model}

The AHP (Saaty, 1977) helps the decision maker in understanding the structuring of decision variables to determine their relative importance in the decision process. A major advantage of the AHP methodology is the ability to convert qualitative constructs into numerical values and allows diverse variables to be compared with one another in a rational and consistent way. The AHP process can be summarized as follows:

\section{Step one - decomposition phase:}

a. Identify all decision alternatives: For this research, the decision alternatives are the software choices.

b. Identify all the criteria for evaluation: the criteria are the evaluation variables. The evaluation variables used in the proposed framework were sourced from various literature (e.g. Al-Harbi, 2001; Chau, 1995; Davis et al., 1994; Jadhav et al., 2009; Khaddaj et al., 2004; Liberatore et al., 2003; Maidamisa et al., 2012; Nandi et al., 2011; Rouyendegh et al., 2011; Saaty, 2008; Uzoka et al., 2008, 2009, 20013, 2016; Vargas et al., 2010; Verner et al., 2009; Verville et al., 2003; Wei et al., 2004; Wei et al., 2005; Zielsdorff et al., 2010). The variables were reduced to manageable factors, using factor analysis. This made it easier to develop a hierarchy of criteria. 


\section{c. Develop the hierarchy of criteria for prioritizations:}

i. Identify the overall goal/objective of the selection

ii. Identify appropriate criteria to satisfy a goal

iii. Identify where appropriate, sub-criteria under each criterion. This is represented in Table 1.

The factor analysis produced 44 variables, which loaded on 14 different constructs. We further grouped the related constructs into six major criteria, namely: cost, functionality, system flexibility, usability, quality and vendor service.

Table 1: IT Project evaluation criteria hierarchy

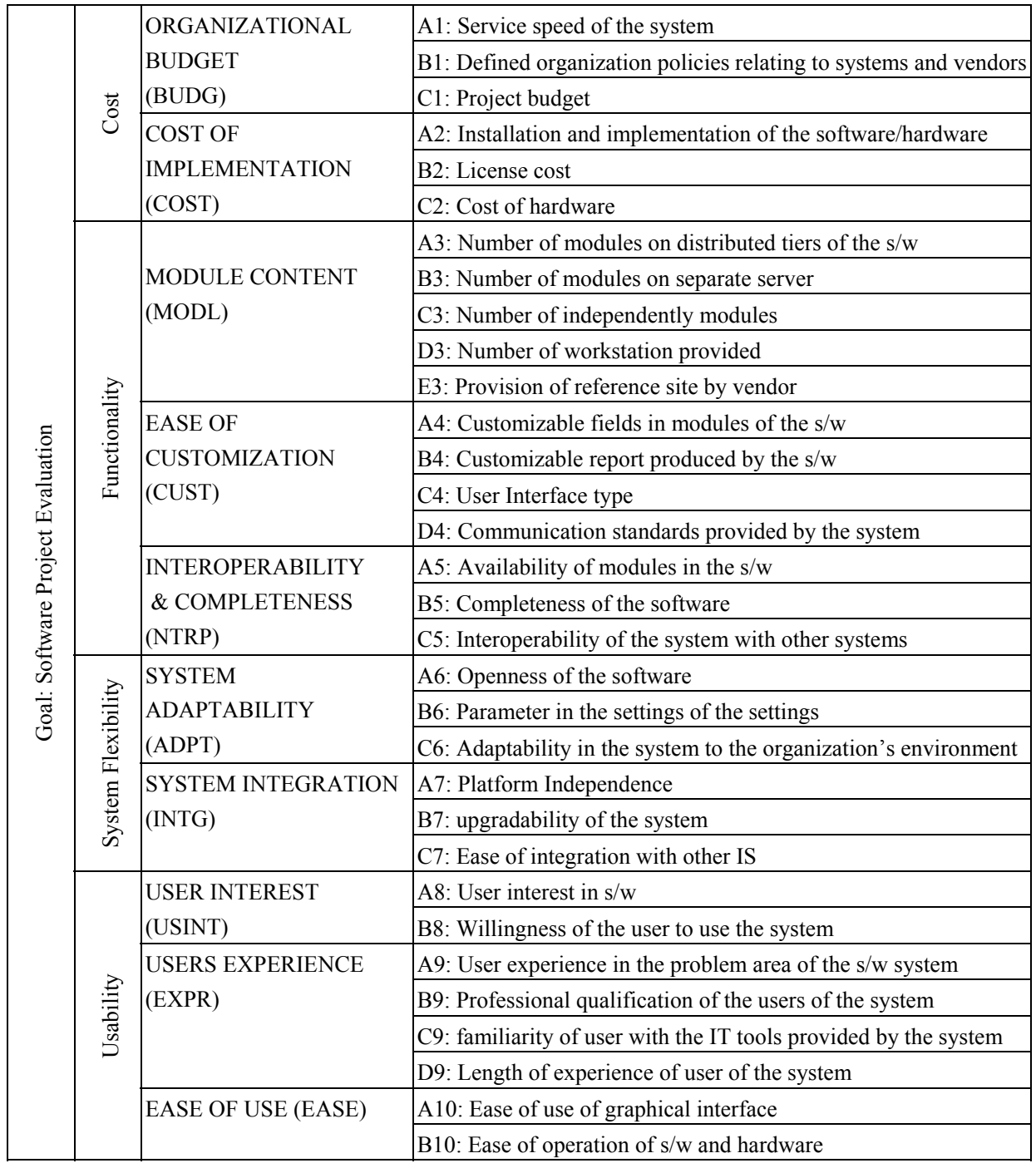


Table 1 cont.

\begin{tabular}{|c|c|c|}
\hline \multirow{5}{*}{ 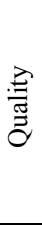 } & \multirow[t]{2}{*}{ RELIABILITY (RELB) } & A11: Stability of both $\mathrm{s} / \mathrm{w}$ and $\mathrm{h} / \mathrm{w}$ \\
\hline & & B11: Recovery ability in case of failure \\
\hline & \multirow{3}{*}{$\begin{array}{l}\text { SYSTEM EFFICIENCY } \\
(\text { EFFCY) }\end{array}$} & A12: Main storage constraint of the system \\
\hline & & B12: Service execution time of the system \\
\hline & & C12: Strength of communication devices \\
\hline \multirow{7}{*}{ 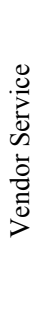 } & \multirow{3}{*}{$\begin{array}{l}\text { VENDOR EXPERIENCE } \\
(\text { VDEX) }\end{array}$} & A13: Length of experience of vendor \\
\hline & & B13: Warranty provided by the vendor \\
\hline & & C13: Past business experience of vendor \\
\hline & \multirow{4}{*}{$\begin{array}{l}\text { VENDOR TECHNICAL } \\
\text { KNOWHOW (VDTK) }\end{array}$} & A14: Ease of implementation of the system \\
\hline & & B14: Good implementation service \\
\hline & & C14: Technical business skills of vendor/developer \\
\hline & & D14: Internal technical knowledge of the vendor/developer \\
\hline
\end{tabular}

\section{Step two - analysis phase}

Establish a priority model by identifying the relative importance of criteria through pairwise comparison. The pairwise comparison is done from the top level of the hierarchy to the bottom level to establish the overall priority index. Measurement of preferences involves a pairwise comparison of evaluation variables, which are verbal statements about the strength of importance of a variable over another, represented numerically on an absolute scale. The comparison is done from the top level of the hierarchy to the bottom level in order to establish the overall priority index.

Let $\mathrm{P}(i, j)$ be a pairwise comparison of two elements $i$ and $j$; where $\{i, j\} \in \mathrm{n}_{\mathrm{k}}\left(\mathrm{n}_{\mathrm{k}}=\right.$ node $k$ of the AHP tree).

The larger the value of $\mathrm{P}(i, j)$, the more $i$ is preferred to $j$ in the priority rating.

The following rules govern the entries in the PWC.

$$
\text { Rule 1: } \mathrm{P}(j, i)=[\mathrm{P}(i, j)]^{-1} \quad(1 \leq \mathrm{P} \leq 9)
$$

Rule 2: If element $i$ is judged to be of equal importance with element $j$, then $\mathrm{P}(i, j)=\mathrm{P}(j, i)=1$; in particular, $\mathrm{P}(i, i)=1$ for all $i$. 
The pairwise comparison (PWC) matrices for levels 2 and 3 criteria are shown in Table 2.

Table 2: Levels 2 and 3 PWC matrix

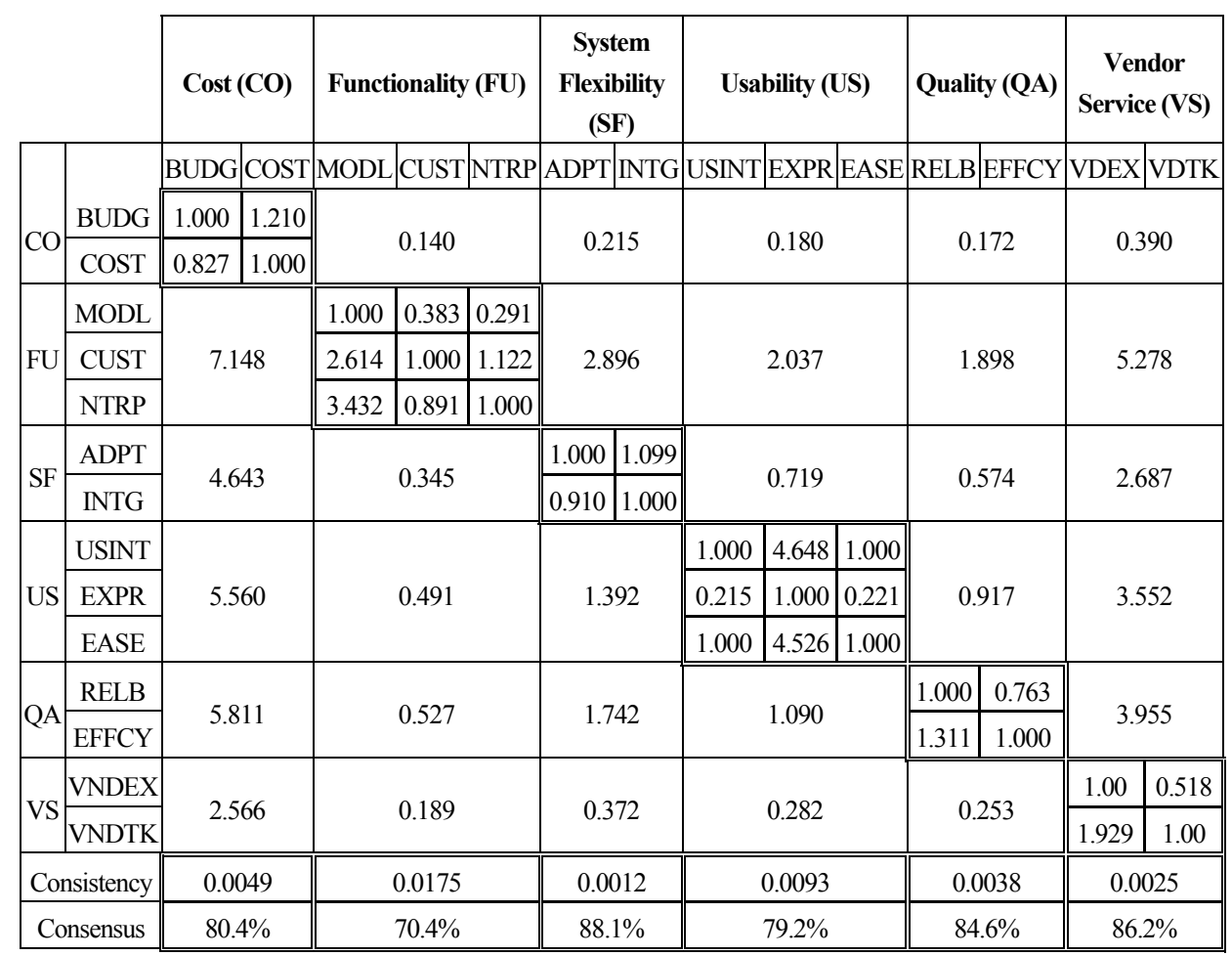

The single-lined cells show the pairwise comparisons for the level 2 factors. For example, a comparison of cost (CO) and Functionality (FU) shows a value of 0.140 , but functionality against cost shows a value of 7.148. This implies that functionality is considered more important than cost by a factor of 7.148 out of 9. The diagonal (double-lined) boxes are the level 3 pairwise comparison matrices. The first is the PWC matrix for the cost factor, while the second diagonal box is the PWC matrix for the functionality factor. Within the functionality factor, ease of customization (CUST) is almost equally valued as interoperability and completeness (NTRP) -1.122 and 0.891 respectively.

Data for the pairwise comparison matrices were obtained from twenty domain experts, who were involved in software projects, either as members of the project management team, or involved in the software acquisition decision. The data were analyzed using Expert Choice software, and AHP templates obtained from http://bpmsg.com. It was important to determine the level of group consensus among the raters. The last row of Table 2 shows group 
consensus of $70 \%$ and above, which validates the utility of the evaluations. One other measure that is important, is the consistency ratios of the pairwise comparison matrices. The ability of AHP to test for consistency is one of the method's greatest strengths. The AHP view of consistency is based on the idea of cardinal transitivity. For example, if criteria $\mathrm{A}$ is twice as important as criteria $\mathrm{B}$, and criteria $\mathrm{B}$ is three times as important as criteria $\mathrm{C}$, then it would imply (by perfect cardinal consistency) that criteria $\mathrm{A}$ be considered six times more important than criteria $\mathrm{C}$. If the domain experts (participants) judge criteria A to be less important than criteria $\mathrm{C}$, it implies that a judgmental error exists, and the prioritization matrix is inconsistent. Our results show consistency ratios which meet the Saaty (1977) threshold of 0.1.

\section{Step three - synthesis}

This involves the computation of eigenvalues and the eigenvector. Synthesis yields the percentage of relative priorities, which is expressed in a linear form to give the eigenvector. The implication of the eigenvector is that it expresses the relative importance of an attribute over another in the minds of the decision maker. The eigenvalues and eigenvector provide a means of obtaining linear relationships among the evaluation variables. Expert Choice was used to synthesize the pairwise comparison judgments. It involves the computation of the eigenvector, which presents linear relationships among the evaluation variables; thus, establishing the priority model.

The level 2 software evaluation criteria give an eigenvector, $\lambda_{1}$, while the level 3 criteria produce the eigenvector, $\lambda_{2}$ for each factor, and the level 4 criteria produce the eigenvector, $\lambda_{3}$ for each sub factor (variable). $\lambda_{1}$, combines with the column vector of level 2 factors to give the project evaluation factor index for level 2 criteria $\left(\mathrm{PEFI}_{1}\right)$, while $\lambda_{2}$, combines with the column vector of the level 3 sub factors to give the project evaluation factor index for level 3 criteria $\left(\mathrm{PEFI}_{2}\right)$ and $\lambda_{3}$ combines with the column vector of the level 4 variables to give the evaluation factor index for level 4 criteria ( $\mathrm{PEFI}_{3}$ ) as shown in (3), (4), (5). Thus, it is possible to evaluate the software project at various levels of factor abstractions. At a higher level, the evaluation could involve just the level 2 criteria (cost, functionality, flexibility, usability, quality, and vendor services). Alternatively, an organization may decide to evaluate their software project in terms of the level 3 factors (Module Content, User's Experience, Vendors Technical Know-how, Ease of Customization, Vendor Experience, System Adaptability, User Interest, Interoperability and Completeness, Reliability, Organizational Budget, Ease of Use, Integration, Cost of Implementation, System Efficiency), or in terms of the 44 level 4 sub-factors/variables. 


$$
\mathrm{PEFI}_{1}=\lambda_{1} \mathrm{~A}_{1}
$$

where $A_{1}$ is the column vector of the level 2 criteria. This gives the $\mathrm{PEFI}_{1}$ as:

$$
\begin{gathered}
\mathrm{PEFI}_{1(\mathrm{GOAL})}=0.035(\mathrm{COS})+0.353(\mathrm{FXN})+0.141(\mathrm{FLX})+0.194(\mathrm{USA}) \\
+0.22(\mathrm{QUA})+0.06(\mathrm{VES}) \\
\mathrm{PEFI}_{2}=\lambda_{2} \mathrm{~A}_{2}
\end{gathered}
$$

where $\mathrm{A}_{2}$ is the column vector of the level 3 criteria. This gives the $\mathrm{PEFI}_{2}$ as:

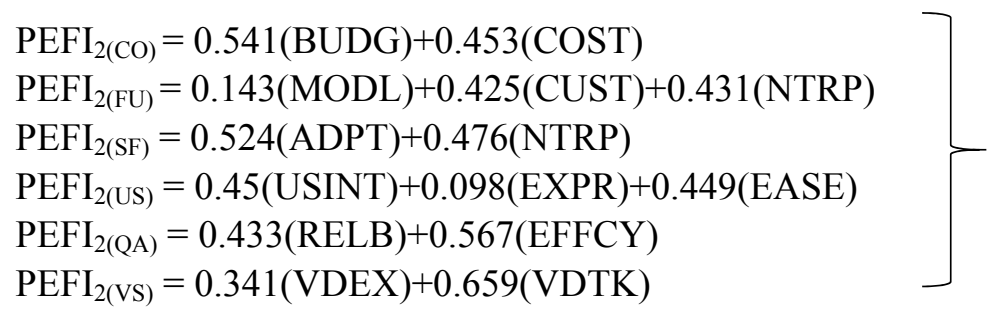

If the evaluator decided to utilize the level 3 factors as the unit of evaluation, then the evaluation weights for the factors would be as shown in Table 3, which is a linear relationship that takes in the qualitative evaluation of the software

\begin{tabular}{|c|c|c|c|c|}
\hline $\begin{array}{c}\text { Level 1: } \\
\text { Goal }\end{array}$ & Level 2: Criteria & Level 3: Factors & \multicolumn{2}{|c|}{ Priority Weight } \\
\hline \multirow{14}{*}{ 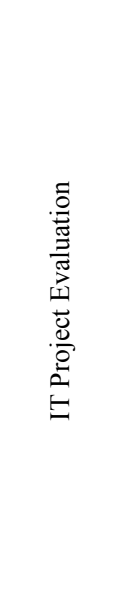 } & \multirow{2}{*}{ Cost } & Organizational Budget (BUDG) & 0.0189 & \multirow{2}{*}{0.0348} \\
\hline & & Cost of Implementation (COST) & 0.0159 & \\
\hline & \multirow{3}{*}{ Functionality } & Module Content (MODL) & 0.0505 & \multirow{3}{*}{0.3526} \\
\hline & & Ease of Customization (CUST) & 0.1500 & \\
\hline & & Interoperability and Openness (NTRP) & 0.1521 & \\
\hline & \multirow{2}{*}{$\begin{array}{c}\text { System } \\
\text { Flexibility }\end{array}$} & System Adaptability (ADPT) & 0.0739 & \multirow{2}{*}{0.141} \\
\hline & & System Integration (INTG) & 0.0671 & \\
\hline & \multirow{3}{*}{ Usability } & User Interest (USINT) & 0.0873 & \multirow{3}{*}{0.1934} \\
\hline & & User Experience (EXPR) & 0.0190 & \\
\hline & & Ease of Use (EASE) & 0.0871 & \\
\hline & \multirow{2}{*}{ Quality } & Reliability (RELB) & 0.0953 & \multirow{2}{*}{0.22} \\
\hline & & System Efficiency (EFFCY) & 0.1247 & \\
\hline & \multirow{2}{*}{ Vendor Service } & Vendor Experience (VDEX) & 0.0205 & \multirow{2}{*}{0.06} \\
\hline & & Vendor Technical Know-How (VDTK) & 0.0395 & \\
\hline
\end{tabular}
project on a numeric scale, to produce an overall evaluation index. The summation of the priority weights is 1 .

Table 3: Level 3 Factors Priority Weights 
It is evident from Table 3 that Functionality had the highest local priority weight of $35.29 \%$, while Cost and Vendor Services had the least priority weights of $3.47 \%$ and $6.26 \%$ respectively The Pareto graph (Figure 2) shows the contributions of each factor to the overall evaluation, and clearly points to the importance of Functionality and Quality factors, which in total, contribute to over $50 \%$ of the factor weightings in the software evaluation and acquisition decision mix.

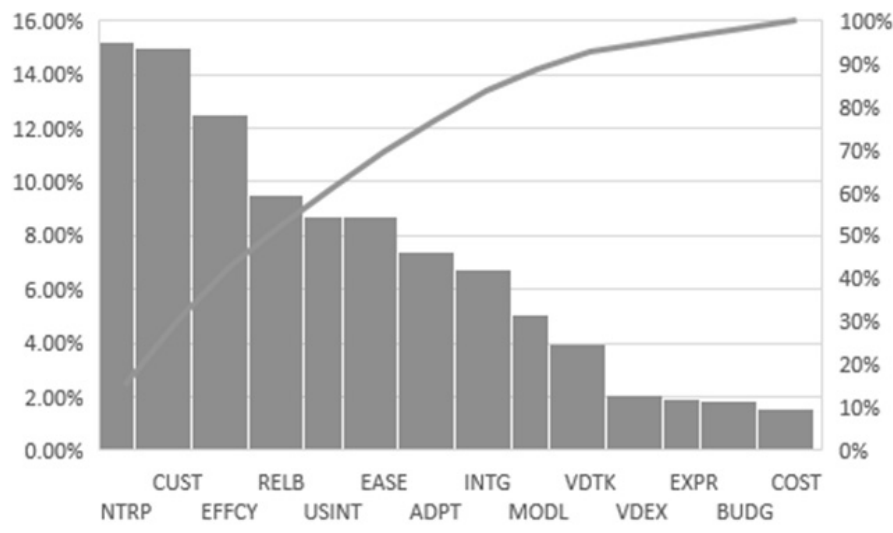

Figure 2: Pareto chart of level 3 factors

Usually, it should be possible to evaluate any software project, based on the level 3 factors; however, organizations that are very process heavy, may decide to further granulate the evaluation into the level 4 sub-criteria. In that case, the project evaluation factor index is given as:

$$
\mathrm{PEFI}_{3}=\lambda_{3} \mathrm{~A}_{3}
$$

where $\mathrm{A}_{3}$ is the column vector of the level 4 criteria. This gives the $\mathrm{PEFI}_{3}$ as:

$$
\begin{aligned}
& \mathrm{PEFI}_{3(\mathrm{BUDG})}=0.576(\mathrm{SES})+0.229(\mathrm{DEP})+0.196(\mathrm{PRB}) \\
& \mathrm{PEFI}_{3(\mathrm{COST})}=0.67(\mathrm{INI})+0.11(\mathrm{LIC})+0.22(\mathrm{COH}) \\
& \mathrm{PEFI}_{3(\mathrm{MODL})}=0.038(\mathrm{NMD})+0.411(\mathrm{NMS})+0.152(\mathrm{NIM})+0.184(\mathrm{NOW})+0.215(\mathrm{POR}) \\
& \mathrm{PEFI}_{3(\mathrm{CUST})}=0.052(\mathrm{CUF})+0.487(\mathrm{CUR})+0.197(\mathrm{INT})+0.264(\mathrm{CST}) \\
& \mathrm{PEFI}_{3(\mathrm{NTRP})}=0.090(\mathrm{AOM})+0.595(\mathrm{COT})+0.315(\mathrm{INO}) \\
& \mathrm{PEFI}_{3(\mathrm{ADPT})}=0.08(\mathrm{OPE})+0.436(\mathrm{PIS})+0.476(\mathrm{AIS}) \\
& \mathrm{PEFI}_{3(\mathrm{NTG})}=0.312(\mathrm{PLI})+0.197(\mathrm{UPG})+0.491(\mathrm{EIT})
\end{aligned}
$$$$
\mathrm{PEFI}_{3 \text { (USINT) }}=0.481(\mathrm{UIN})+0.519 \text { (WTU) }
$$$$
\mathrm{PEFI}_{3(\mathrm{EXPR})}=0.052(\mathrm{UEP})+0.407(\mathrm{PQU})+0.393(\mathrm{FRU})+0.147(\mathrm{LOU})
$$$$
\mathrm{PEFI}_{3(\mathrm{EASE})}=0.552(\mathrm{EGI})+0.448(\mathrm{EOP})
$$$$
\mathrm{PEFI}_{3 \text { (RELB) }}=0.50(\mathrm{STS})+0.50(\mathrm{RAB})
$$$$
\mathrm{PEFI}_{3(\mathrm{EFFCY})}=0.077(\mathrm{MAS})+0.644(\mathrm{SET})+0.279(\mathrm{SOC})
$$$$
\mathrm{PEFI}_{3(\mathrm{VNDEX})}=0.114(\mathrm{LOE})+0.184(\mathrm{WPV})+0.701(\mathrm{PBE})
$$$$
\mathrm{PEFI}_{3(\mathrm{VNDTK})}=0.055 \text { (EOI) }+0.159 \text { (GIS) }+0.437 \text { (TBS) }+0.349 \text { (ITK) }
$$ 
Combining (4), (6) and (8), we produce the following Aggregate Project Evaluation Factor Index (APEFI), which serves as a linear equation for the evaluation of any given software project:

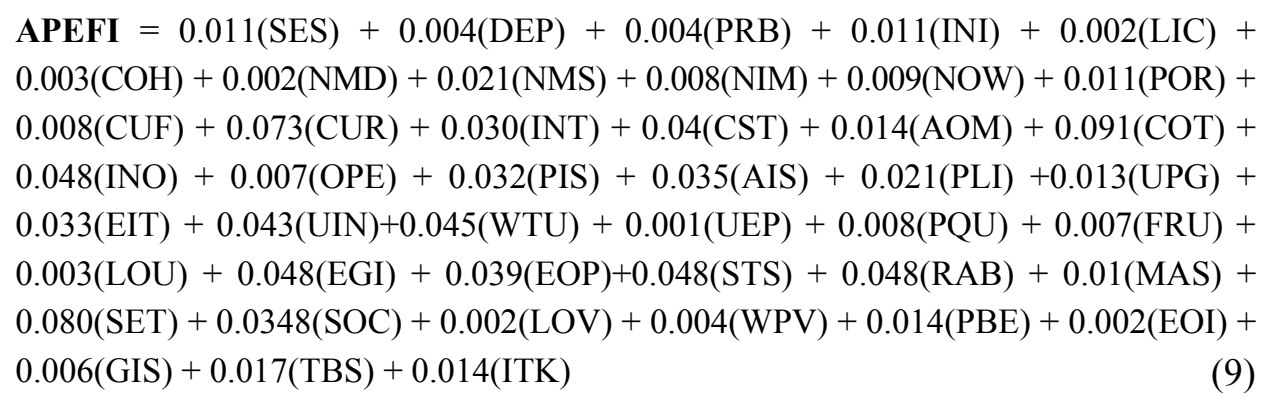

\section{Model evaluation and results}

To test the evaluation system, we visited ten organizations to identify the individual(s) who had the competence to make decisions on software projects based on: 1) their positions in the respective organizations, and 2) involvement in information systems projects. In some organizations, we identified more than one person who had the competence. In such situations, an individual was requested to coordinate the group decision process in arriving at one group evaluation for their existing major software system or a software project being proposed by the organizations. Our goal was to collect simple data that would be useful in testing the utility of the AHP model for evaluation of software projects. A survey was administered to each organization that agreed to participate in the evaluation exercise. The survey utilized the 44 level 4 evaluation variables and provided the evaluators with a five-point linguistic Likert scale (poor, fair, good, very good, excellent). The snap shot of results of the final evaluation are shown in Appendix 1.

The APEFI was applied to data in Appendix 1 to obtain the final evaluation of each organization's software system. This was done through the following:

$$
S_{i=} \sum_{k=1}^{n} R_{i k} X_{k}
$$

where: $S_{i}$ is the evaluation score of organization $i$, $R_{i k}$ is the rating of organization $i$ on variable $k$, $X_{k}$ is the APEFI value of variable $k$, $n$ is he number of level 4 evaluation variables. 
An illustration using organization 1 is given below:

$\mathrm{APEFI}=0.011(4)+0.004(3)+0.004(4)+0.011(3)+0.002(4)+0.003(4)+0.002(4)+$
$0.021(5)+0.008(3)+0.009(4)+0.011(3)+0.008(3)+0.073(3)+0.030(3)+0.04(4)+$
$0.014(5)+0.091(4)+0.048(4)+0.007(4)+0.032(2)+0.035(3)+0.021(2)+0.013(5)+$
$0.033(4)+0.043(4)+0.045(3)+0.001(4)+0.008(5)+0.007(3)+0.003(5)+0.048(4)+$
$0.039(4)+0.048(4)+0.048(4)+0.01(4)+0.080(3)+0.0348(4)+0.002(4)+0.004(4)+$
$0.014(3)+0.002(3)+0.006(4)+0.017(3)+0.014(3)=3.444$.

The summary of the evaluation results, before and after the application of the AHP model is presented in Table 4.

Table 4: Evaluation summaries

\begin{tabular}{|c|c|c|c|c|}
\hline \multirow{2}{*}{ Organization } & \multicolumn{2}{|c|}{ Pre-AHP Evaluation } & \multicolumn{2}{c|}{ Post-AHP Evaluation } \\
\cline { 2 - 5 } & total score & rank & total score & rank \\
\hline 1 & 165 & 3 & 3.47 & 5 \\
\hline 2 & 167 & 2 & 3.58 & 4 \\
\hline 3 & 141 & 8 & 2.91 & 9 \\
\hline 4 & 140 & 9 & 3.17 & 6 \\
\hline 5 & 201 & 1 & 4.43 & 1 \\
\hline 6 & 164 & 4 & 3.94 & 2 \\
\hline 7 & 126 & 10 & 2.81 & 10 \\
\hline 8 & 143 & 7 & 3.00 & 8 \\
\hline 9 & 145 & 6 & 3.06 & 7 \\
\hline 10 & 159 & 5 & 3.69 & 3 \\
\hline
\end{tabular}

The results show that the application of AHP refined the initial evaluations by taking into cognizance, the priorities attached to the evaluation variables. After the application of AHP, organization 4, 6, and 10 had improvements in the rankings of their information systems, while organizations $1,2,3,8$ and 9 saw a drop in the ranking of their information systems; organizations 5 and 7 did not see any change in the ranking of their system; organization 5 being the best and organization 7 being the worst. While the primary aim of this paper was not to rank individual organization's software systems, we used this to demonstrate the utility of the system in ranking various vendors' proposals. Organizations could also apply the AHP model in the evaluation of their existing information systems.

The AHP model also reveals the relative importance of various factors in the software/vendor evaluation process. The results show that functionality, quality and usability are very critical in the software evaluation decision, while cost and vendor service rank low in decision process. We briefly discuss the findings, relating to the level 2 evaluation criteria. 


\section{Cost}

Cost had a priority weight of $3.48 \%$, the least weight among the evaluation factors, which implies that the cost of a software project proposal is not considered very critical in the evaluation and selection of software projects presented by vendors. This aligns with the research presented in Jain et al. (2008) and in Khan et al. (2011) where cost was not found to be the driving factor in the process of selecting vendors for software development. Also, in Lai et al. (1999) cost was found to be relatively unimportant in software selection process. Client organizations need to lay more emphasis on the other evaluation factors with the view to selecting an appropriate software project proposal that best satisfy the needs of the client organization (i.e. end users), and improves the quality of work they perform (Lai et al., 1999). It is worthy to note that organizations are more willing to accept the cost of software project in so far as the functionality and quality meet their requirements (Khan et al., 2011). According to Stefanou (2001), client organization works within its budget; however, if a software solution is found to provide the organization with best service, there will be the need to strike a cost balance in order not to play down on other software factors such as quality, functionality, effectiveness, efficiency etc.

\section{Functionality}

Functionality had the highest priority weight of $35.26 \%$, which makes it a key factor in choosing software solutions for organizations. Functionality relates with the functional requirements of the client organization; thus, if a software project proposal, based on the client's judgments, has a high functionality rating, there is the tendency that such software would likely meet most of the organization's functional requirements. Khan et al. (2011) and Lai et al. (1999) considered excellent functional behavior of a given software solution to be key determinants in the software selection process. In this study, the following sub-factors were considered under functionality: module content, ease of customization, interoperability and openness. The highest level 3 criteria priority weights were recorded by ease of customization $(15.0 \%)$ and interoperability and openness (15.2\%). Many organizations are moving toward enterprise resource planning (ERP) software systems, and consider software interoperability to be a very crucial attribute in software evaluation (Bertram et al., 2016; Keil and Tiwana, 2006).

\section{System Flexibility}

The priority weight for system flexibility was $14.1 \%$. The elements considered under flexibility were system adaptability (ADPT) (0.0739) and system integration (INTG) (0.0671). These are non-functional requirements that have 
some level of significance in the selection of software solutions for company services. The importance of system flexibility, especially in ERP environments has been emphasized in Atal et al. (2016), Khan et al. (2011), Uzoka et al. (2008), Uzoka (2009) and aligns with the need to have systems that could easily be adapted to meet the dynamic needs of organizations.

\section{Usability}

This is a non-functional requirement having priority value of $19.34 \%$. The priority attached to usability underscores the need for user friendly systems, which has been severally emphasized in literature such as Abdelaziz et al. (2016), Lewis (2014), Uzoka (2009). In emphasizing the importance of usability of software systems in the overall performance of the organization, the authors in Engelbrecht et al. (2017) noted that business managers often underestimate its impact on processes and people; and further suggested that organizations embrace the culture of usability testing and training, especially with enterprise systems. It was recommended in Lewis (2014) that software practitioners should emphasize iterative formative (rather than summative) usability testing, using one of the available standard usability instruments, as a means of improving objective and perceived usability. The usability factors identified in our study [User Interest (0.0873), User Experience (0.0190) and Ease of Use (0.0871)] have been severally recognized in technology adoption as having significant impacts on the potential user's intention to adopt technology (including software).

\section{Quality}

Software quality has one of the high priority weights (22\%) in the AHP model, pointing to its importance in the software evaluation process. Since organizations are prepared to invest in information systems, they would obviously expect high value from such investments, especially in a global software landscape that is characterized by many vendors and products. Finding a product that is suitable for the organization's needs is a key challenge in the software selection process. Our study further emphasizes the quality factors of reliability and efficiency, which account for $9.53 \%$ and $12.47 \%$ respectively of the level 3 evaluation factor weights. The importance of quality factors in the software evaluation process is emphasized in ALMohiza et al. (2016), while Uzoka et al. (2008) found quality to be of utmost importance in the selection of ERP systems. 


\section{Vendor Service}

The experience of vendors vis-à-vis their technical know-how cannot be underestimated while considering vendors to choose for a given project (Al-Harbi, 2001; Jain et al., 2008). The priority weight of vendor service attribute is the second lowest compared to other factors (priority weight $=0.06$ ). This presents an interesting result, which is at variance with previous studies that emphasized the importance of vendor's support and technical know-how in the software selection process (Jain et al., 2008; Uzoka et al., 2008). Similar to cost, vendor service seems not to matter so much, especially because many medium to large organizations have in-house technical competence to manage and maintain their software system.

\section{Limitations}

Data sample used for this study was small, which could impact on the generalization of our model. Moreover, we did not consider implementation process for selected software project. A wrong implementation process by the client organization could be responsible for failed software solution in an organization. Therefore, a future research could incorporate an implementation framework that focuses on the cause and effect relationship that software project selection process activities/results have on the implementation process. We also note that the AHP model was developed using pairwise comparison information provided by experts in software project management. This model could be better generalized with a larger number of domain experts in various project environments, with a good diversity of constraints.

\section{Conclusion}

This study provides organizations with valuable knowledge that would prompt them to make significant changes in the manner in which they currently proceed with the selection of any software project proposal, which in turn, could result in substantial savings in terms of economics (actual costs, time, and improved administrative procedures). The proposed system will enable: 1) active involvement of the users in the client organization in the software selection and development process; 2) the software vendor to have intimate relationship with the entire management of the client organization, thus minimizing potential challenges during users' requirements gathering; 3) users to easily accept, adopt and understand and use the software when deplored. This study has helped to provide significant criteria that management of organizations could utilize to 
evaluate the IT solutions proposed by IT vendors and these criteria align with the terms in the IT procurement policy presented in IT Procurement Policy (2005). It helps to enrich the knowledge of client organizations on the theoretical and practical principles of the selection process for valuable IT application package with the ultimate goal of end-user satisfaction. AHP through its structured hierarchy of decision levels and pair wise comparison of elements for value judgment is more effective than utility models and scoring charts in working with semi-quantitative data as realistic inputs to the priority-setting agenda. They help to overcome in a significant way, the fuzzy nature of quantitative information related to deliverable, logistics, and outcome. In the resource constrained situation of the developing countries, AHP provides a vital tool to select and rank projects based on judgmental evaluation through peer ratings. AHP provides a comprehensive and rational framework for structuring a decision problem, for representing and quantifying its elements, for relating those elements to overall goals, and for evaluating alternative solutions. It also considers a set of evaluation criteria, and a set of alternative scenarios among which the best decision is to be made. It generates a weight for each evaluation criterion and scenario according to the information provided by the decision maker. AHP is effective in dealing with complex decision making because it reduces complex decisions to a series of pairwise comparisons and reduces the bias in the decision-making process because it also checks the consistency of the decision maker's evaluations. The system proposed in this study could be scaled with more data, to a generalizable level that could serve as a standard model for software system evaluation and selection.

\section{References}

Abdelaziz T.M., Maatuk A.M., Rajab F. (2016), An Approach to Improvement the Usability in Software Products, International Journal of Software Engineering \& Applications (IJSEA), $7(2), 11-18$.

Akinnuwesi B.A., Uzoka F.M.E. (2017), Assessment of Software Project Proposal using Analytical Hierarchy Process: A Framework, Journal of Research and Review in Science, 4(1), Publication of Faculty of Science, Lagos State University, Lagos, Nigeria, 44-55.

Akinnuwesi B.A., Uzoka F.M., Olabiyisi S.O., Omidiora E.O. (2012), A Framework for User-centric Model for Evaluating the Performance of Distributed Software System Architecture, Expert Systems with Applications, 39(10), 9323-9339.

Akinnuwesi B.A., Uzoka F.M., Olabiyisi S.O., Omidiora E.O., Fiddi P. (2013), An Empirical Analysis of End-user Participation in Software Development Projects in a Developing Country Context, The Electronic Journal of Information Systems in Developing Countries, 58(6), 1-25.

Akinnuwesi B.A., Uzoka F.M., Osamiluyi A.O. (2013c), Neuro-Fuzzy Expert System for Evaluating the Performance of Distributed Software System Architecture, Expert Systems with Applications, 40(9), 3313-3327. 
Al-Harbi K.M.A.-S. (2001), Application of the AHP in Project Management, International Journal of Project Management, 19(1), 19-27.

ALMohiza M.A., Sparto P.J., Marchetti G.F., Delitto A., Furman J.M., Miller D.L., Whitney S.L. (2016), A Quality Improvement Project in Balance and Vestibular Rehabilitation and Its Effect on Clinical Outcomes, Journal of Neurologic Physical Therapy, 40(2), 90-99.

Atal V., Bar T., Gordon S. (2016), Project Selection: Commitment and Competition, Games and Economic Behavior, (96), 30-48.

Bertram V., Manhart P., Plotnikov D., Rumpe B., Schulze C., Wenckstern M. von (2016), Infrastructure to Use OCL for Runtime Structural Compatibility Checks of Simulink Models, Modellierung, 109-116.

Bertram V., Roth A., Rumpe B., Wenckstern M. von (2016), Extendable Toolchain for Automatic Compatibility Checks.

Bredillet C.N. (2010), Blowing Hot and Cold on Project Management, Project Management Journal, 41(3), 4-20.

Buss M.D.J. (1983), How to Rank Computer Projects, Harvard Business Review, 61(1), 118-125.

Chau P.Y. (1995), Factors Used in the Selection of Packaged Software in Small Businesses: Views of Owners and Managers, Information \& Management, 29(2), 71-78.

Davis L., Williams G. (1994), Evaluating and Selecting Simulation Software Using the Analytic Hierarchy Process, Integrated Manufacturing Systems, 5(1), 23-32.

Engelbrecht J., Johnston K.A., Hooper V. (2017), The Influence of Business Managers' IT Competence on IT Project Success, International Journal of Project Management, 35(6), 994 1005.

Hares J., Royle D. (1994), Measuring the Value of Information Technology, John Wiley and Sons, Inc., New York.

He J., Butler B.S., King W.R. (2007), Team Cognition: Development and Evolution in Software Project Teams, Journal of Management Information Systems, 24(2), 261-292.

Hoffer J., George J., Valacich J. (2016). Modern Systems Analysis and Design, (8 ${ }^{\text {th }}$ Edition), Pearson, Essex.

Hwang C.-L., Yoon K. (2012), Multiple Attribute Decision Making: Methods and Applications a State-of-the-art Survey, Springer Verlag, New York.

Ika L.A. (2009), Project Success as a Topic in Project Management Journals, Project Management Journal, 40(4), 6-19.

IT Procurement Policy 2005, Information Technology (IT) Procurement Policy.

Jadhav A.S., Sonar R.M. (2009), Evaluating and Selecting Software Packages: A Review, Information and Software Technology, 51(3), 555-563.

Jadhav A.S., Sonar R.M. (2011), Framework for Evaluation and Selection of the Software Packages: A Hybrid Knowledge Based System Approach, Journal of Systems and Software, 84(8), 1394-1407.

Jain V., Benyoucef L., Bennett D., Deep A., Guttridge P., Dani S., Burns N. (2008), Investigating Factors Affecting ERP Selection in Made-to-order SME Sector, Journal of Manufacturing Technology Management, 19(4), 430-446.

Kahraman C., Büyüközkan G., Ruan D. (2004), Measuring Software Development Value Using Fuzzy Logic, [in:] D. Ruan, X. Zeng (eds.), Intelligent Sensory Evaluation: Methodologies and Applications, Springer, 285-308.

Keil M., Tiwana A. (2006), Relative Importance of Evaluation Criteria for Enterprise Systems: A Conjoint Study, Information Systems Journal, 16(3), 237-262.

Khaddaj S., Horgan G. (2004), The Evaluation of Software Quality Factors in Very Large Information Systems, Electronic Journal of Information Systems Evaluation, 7(1), 43-48. 
Khan S.U., Niazi M., Ahmad R. (2011), Factors Influencing Clients in the Selection of Offshore Software Outsourcing Vendors: An Exploratory Study Using a Systematic Literature Review, Journal of Systems and Software, 84(4), 686-699.

Lai V.S., Trueblood R.P., Wong B.K. (1999), Software Selection: A Case Study of the Application of the Analytical Hierarchical Process to the Selection of a Multimedia Authoring System, Information \& Management, 36(4), 221-232.

Lewis J.R. (2014), Usability: Lessons Learned ... and Yet to be Learned, International Journal of Human-Computer Interaction, 30(9), 663-684.

Liberatore M.J., Pollack-Johnson B. (2003), Factors Influencing the Usage and Selection of Project Management Software, IEEE Transactions on Engineering Management, 50(2), 164-174.

Maidamisa A.A., Ahmad R., Aziz M.I.A. (2012), Selecting the Appropriate Decision Alternatives Using SM and AHP, International Journal of Computer Applications, 37(10), 14-18.

Melone N., Wharton T. (1984), Strategies for MIS Project Selection, Journal of Systems Management, 35(2), 26-33.

Meso P., Jain R. (2006), Agile Software Development: Adaptive Systems Principles and Best Practices, Information Systems Management 23(3), 19-30.

Molla A., Licker P.S. (2005), eCommerce Adoption in Developing Countries: A Model and Instrument, Information \& Management, 42(6), 877-899.

Muralidhar K., Santhanam R., Wilson R.L. (1990), Using the Analytic Hierarchy Process for Information System Project Selection, Information \& Management, 18(2), 87-95.

Nandi S., Paul S., Phadtare M. (2011), An AHP-based Construction Project Selection Method, Decision, 38(1), 91-118.

Niessink F., Van Vliet H. (1999), Measurements Should Generate Value, Rather than Data [Software Metrics], Software Metrics Symposium, 1999, Proceedings. Sixth International, IEEE, 31-38.

Oppermann R., Reiterer H. (1997), Software Evaluation Using the 9241, Behaviour and Information Technology, 16(4/5), 232-245.

Patanakul P., Iewwongcharoen B., Milosevic D. (2010), An Empirical Study on the Use of Project Management Tools and Techniques Across Project Life-cycle and Their Impact on Project Success, Journal of General Management, 35(3), 41-65.

Rivard S., Dupré R. (2009), Information Systems Project Management in PMJ: A Brief History, Project Management Journal, 40(4), 20-30.

Rouyendegh B.D., Erkan T.E. (2011), ERP System Selection by AHP Method: Case Study from Turkey, International Journal of Business and Management Studies, 3(1), 39-48.

Saaty T.L. (1977), A Scaling Method for Priorities in Hierarchical Structures, Journal of Mathematical Psychology, 15(3), 234-281.

Saaty T.L. (1990), How to Make a Decision: The Analytic Hierarchy Process, European Journal of Operational Research, 48(1), 9-26.

Saaty T.L. (2008), Decision Making with the Analytic Hierarchy Process, International Journal of Services Sciences, 1(1), 83-98.

Seong Leem C., Yoon Y. (2004), A Maturity Model and an Evaluation System of Software Customer Satisfaction: The Case of Software Companies in Korea, Industrial Management \& Data Systems, 104(4), 347-354.

Sherer S.A. (2004), IS Project Selection: The Role of Strategic Vision and IT Governance, System Sciences, Proceedings of the 37th Annual Hawaii International Conference on, IEEE.

Stefanou C.J. (2001), A Framework for the Ex-ante Evaluation of ERP Software, European Journal of Information Systems, 10(4), 204-215. 
Uzoka F.M., Abiola R.O., Nyangeresi R. (2008), Influence of Product and Organizational Constructs on ERP Acquisition Using an Extended Technology Acceptance Model, International Journal of Enterprise Information Systems, 4(2), 67-70.

Uzoka F.M., Akinnuwesi B.A., Oluwole N., Adekoya, A.F., Egbekunle O.Y. (2016), Identifying Factors for Evaluating Software Project Proposals, International Journal of Quality Engineering and Technology, 6(1/2), 93-114.

Uzoka F.M., Fedoruk A., Osakwe C., Osuji J., Gibb K. (2013), A Multi-criteria Framework for Assessing Scholarship Based on Boyer's Scholarship Model, Information Knowledge Systems Management, 12(1), 25-51.

Uzoka F.M.E. (2009), Examining the Effects of TAM Constructs on Organizational Software Acquisition Decision, Information Resources Management Journal (IRMJ), 22(3), 40-58.

Vargas R.V. (2010), Using the Analytic Hierarchy Process (AHP) to Select and Prioritize Projects in a Portfolio, PMI Global Congress 2010 North America, Available: http://www. ricardo-vargas.com/wp-content/uploads/downloads/articles/ricardo_vargas_ahp_project_ selection_en.pdf, Access Date: July 30, 2016, 2010.

Verner J., Sampson J., Cerpa N., Bleistein S. (2009), What Factors Lead to Software Project Failure and Whose Fault Was It?, Ingénierie des Systèmes d'Information, 14(4), 55-75.

Verville J., Halingten A. (2002), An Investigation of the Decision Process for Selecting an ERP Software: The Case of ESC, Management Decision, 40(3), 206-216.

Verville J., Halingten A. (2003), A Six Stage Model of the Buying Process for ERP Software, Industrial Marketing Management, (32), 585-594.

Wei C.-C., Chien C.F., Wang M.-J.J. (2005), An AHP-based Approach to ERP System Selection, International Journal of Production Economics, 96(1), 47-62.

Wei C.-C., Wang M.-J.J. (2004), A Comprehensive Framework for Selecting an ERP System, International Journal of Project Management, 22(2), 161-169.

Williams J.B., Gibbon M., First M.B., Spitzer R.L., Davies M., Borus J., Howes M.J., Kane J., Pope H.G., Rounsaville B. (1992), The Structured Clinical Interview for DSM-III-R (SCID): II. Multisite Test-retest Reliability, Archives of General Psychiatry, 49(8), 630-636.

Yoon K.P., Hwang C.-L. (1995), Multiple Attribute Decision Making: An Introduction, SAGE Publications, London.

Zielsdorff C., McGinnis C., Daim T., Basoglu N. (2010), Enterprise Resource Planning (ERP) Selection for a Medical Devices Manufacturing Company, International Journal of Business Information Systems, 6(2), 265-293. 


\section{Appendix 1}

\section{Raw Evaluation of Organizational Software Systems}

\begin{tabular}{|c|c|c|c|c|c|c|c|c|c|c|c|}
\hline Variables & GPW & DM1 & DM2 & DM3 & DM4 & DM5 & DM6 & DM7 & DM8 & DM9 & DM10 \\
\hline A1 & 0.011 & 4 & 4 & 4 & 3 & 3 & 3 & 3 & 4 & 3 & 4 \\
\hline B1 & 0.004 & 3 & 3 & 3 & 3 & 4 & 3 & 3 & 4 & 2 & 3 \\
\hline $\mathrm{C} 1$ & 0.004 & 4 & 4 & 4 & 3 & 5 & 3 & 4 & 4 & 4 & 4 \\
\hline $\mathrm{A} 2$ & 0.011 & 3 & 4 & 4 & 3 & 5 & 3 & 4 & 4 & 3 & 3 \\
\hline $\mathrm{B} 2$ & 0.002 & 4 & 4 & 4 & 2 & 5 & 3 & 4 & 3 & 3 & 4 \\
\hline $\mathrm{C} 2$ & 0.003 & 4 & 3 & 3 & 2 & 5 & 3 & 4 & 3 & 4 & 3 \\
\hline A3 & 0.002 & 4 & 4 & 5 & 3 & 5 & 3 & 4 & 5 & 5 & 4 \\
\hline B3 & 0.021 & 5 & 5 & 4 & 3 & 5 & 3 & 4 & 5 & 5 & 4 \\
\hline C3 & 0.008 & 3 & 3 & 3 & 3 & 4 & 3 & 3 & 3 & 2 & 3 \\
\hline D3 & 0.009 & 4 & 4 & 4 & 4 & 4 & 3 & 3 & 5 & 3 & 4 \\
\hline E3 & 0.011 & 3 & 4 & 3 & 4 & 4 & 3 & 3 & 3 & 3 & 4 \\
\hline A4 & 0.008 & 3 & 4 & 3 & 4 & 3 & 5 & 3 & 3 & 3 & 4 \\
\hline B4 & 0.073 & 3 & 3 & 2 & 3 & 3 & 5 & 3 & 3 & 3 & 3 \\
\hline $\mathrm{C} 4$ & 0.030 & 3 & 3 & 3 & 3 & 5 & 5 & 3 & 3 & 3 & 3 \\
\hline D4 & 0.040 & 4 & 4 & 2 & 3 & 5 & 5 & 3 & 4 & 3 & 4 \\
\hline A5 & 0.014 & 5 & 5 & 3 & 4 & 5 & 5 & 3 & 4 & 4 & 5 \\
\hline B5 & 0.091 & 4 & 4 & 3 & 3 & 5 & 5 & 3 & 3 & 3 & 4 \\
\hline $\mathrm{C} 5$ & 0.048 & 4 & 4 & 2 & 4 & 5 & 4 & 3 & 4 & 2 & 4 \\
\hline A6 & 0.007 & 4 & 5 & 3 & 3 & 4 & 4 & 3 & 5 & 4 & 4 \\
\hline B6 & 0.032 & 2 & 3 & 2 & 4 & 3 & 4 & 2 & 2 & 3 & 2 \\
\hline C6 & 0.035 & 3 & 3 & 2 & 4 & 4 & 4 & 2 & 2 & 3 & 3 \\
\hline A7 & 0.021 & 2 & 3 & 2 & 4 & 4 & 3 & 2 & 2 & 2 & 3 \\
\hline B7 & 0.013 & 5 & 4 & 3 & 2 & 4 & 3 & 2 & 3 & 3 & 4 \\
\hline $\mathrm{C} 7$ & 0.033 & 4 & 3 & 3 & 2 & 5 & 3 & 3 & 3 & 4 & 4 \\
\hline A8 & 0.043 & 4 & 2 & 3 & 2 & 5 & 3 & 3 & 4 & 3 & 4 \\
\hline B8 & 0.045 & 3 & 3 & 3 & 2 & 5 & 3 & 2 & 3 & 1 & 5 \\
\hline A9 & 0.001 & 4 & 4 & 3 & 3 & 5 & 3 & 3 & 4 & 3 & 3 \\
\hline B9 & 0.008 & 5 & 5 & 4 & 4 & 5 & 4 & 4 & 5 & 4 & 4 \\
\hline C9 & 0.007 & 3 & 4 & 3 & 3 & 4 & 4 & 3 & 3 & 3 & 3 \\
\hline D9 & 0.003 & 5 & 5 & 4 & 3 & 4 & 5 & 3 & 4 & 5 & 5 \\
\hline A10 & 0.048 & 4 & 5 & 3 & 3 & 4 & 4 & 3 & 4 & 4 & 5 \\
\hline B10 & 0.039 & 4 & 5 & 4 & 3 & 5 & 5 & 3 & 3 & 4 & 5 \\
\hline A11 & 0.048 & 4 & 4 & 5 & 4 & 5 & 5 & 3 & 3 & 3 & 4 \\
\hline B11 & 0.048 & 4 & 5 & 4 & 4 & 5 & 5 & 3 & 3 & 4 & 4 \\
\hline A12 & 0.010 & 4 & 5 & 4 & 4 & 5 & 4 & 3 & 3 & 4 & 4 \\
\hline B12 & 0.080 & 3 & 3 & 2 & 4 & 5 & 4 & 3 & 2 & 3 & 4 \\
\hline $\mathrm{C} 12$ & 0.035 & 4 & 4 & 3 & 4 & 5 & 4 & 3 & 3 & 4 & 4 \\
\hline A13 & 0.002 & 4 & 4 & 2 & 3 & 5 & 5 & 3 & 2 & 3 & 3 \\
\hline B13 & 0.004 & 4 & 3 & 3 & 3 & 5 & 3 & 3 & 3 & 3 & 2 \\
\hline C13 & 0.014 & 3 & 4 & 4 & 3 & 5 & 3 & 3 & 3 & 3 & 3 \\
\hline A14 & 0.002 & 3 & 2 & 2 & 3 & 5 & 3 & 2 & 2 & 3 & 2 \\
\hline B14 & 0.006 & 4 & 4 & 4 & 3 & 5 & 3 & 3 & 3 & 4 & 3 \\
\hline $\mathrm{C} 14$ & 0.017 & 3 & 3 & 3 & 3 & 5 & 3 & 3 & 2 & 3 & 2 \\
\hline D14 & 0.014 & 3 & 3 & 4 & 3 & 5 & 3 & 3 & 3 & 4 & 3 \\
\hline TOTAL & 1.005 & 165 & 167 & 141 & 140 & 201 & 164 & 126 & 143 & 145 & 159 \\
\hline RANK & & 3 & 2 & 8 & 9 & 1 & 4 & 10 & 7 & 6 & 5 \\
\hline
\end{tabular}

Key: GPW $=$ Global Priority Weight, DM1...DM10 represent the system evaluations by the ten decision makers (DM) in the sampled organizations. 